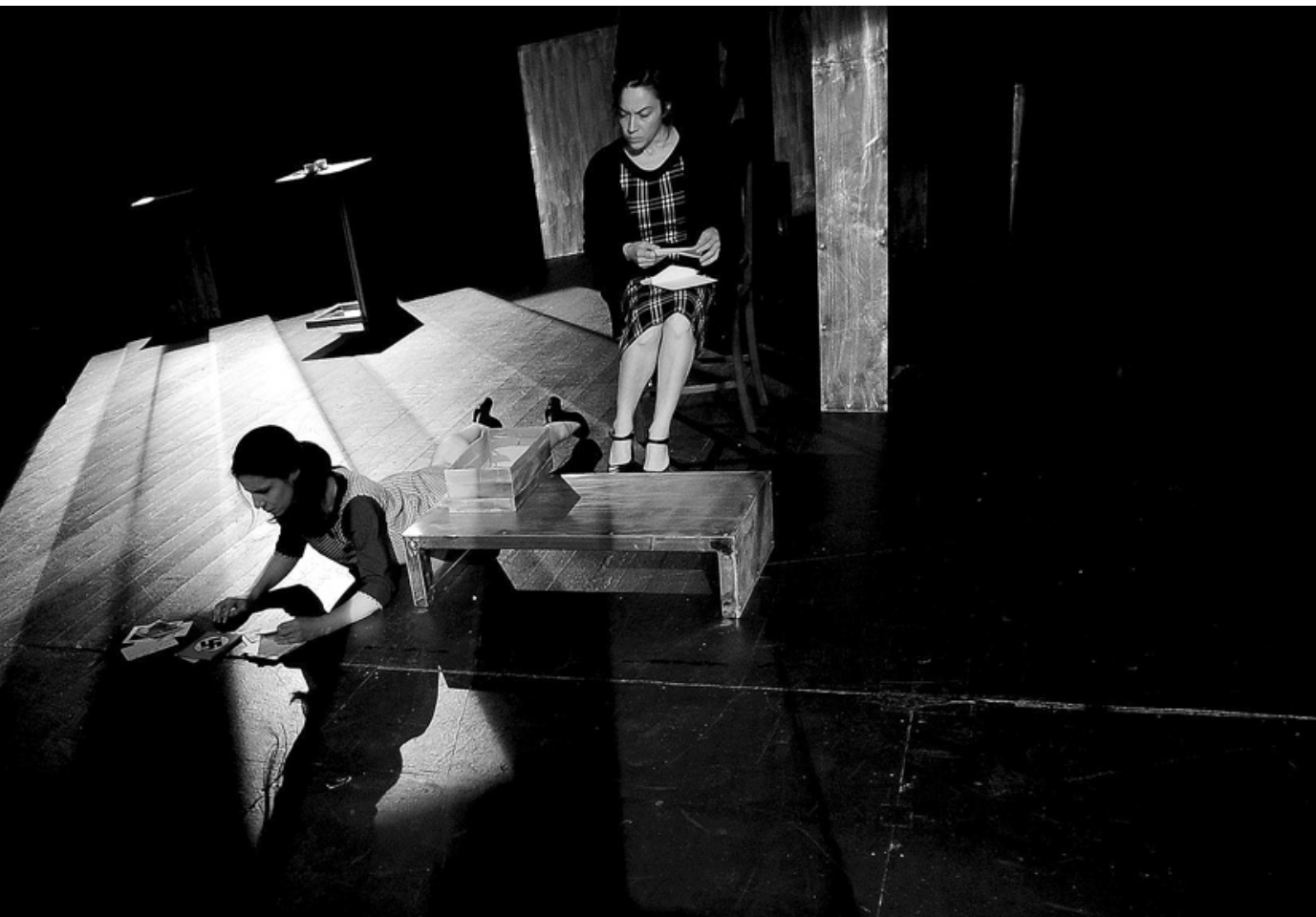

\title{
A má consciência dos moderados
}

\section{Constança Carvalho Homem}

Titulo:A pedra. Autor: Marius von Mayenburg. Tradutor: Ricardo Braun. Encenação: Cristina Carvalhal. Cenografia:Cláudia Armanda. Figurinos: Catarina Barros. Desenho de som: Luis Aly. Desenho de luz: Nuno Meira. Interpretação: Daniel Pinto, Joana Carvalho, Júlia Correia, Maria do Céu Ribeiro, Sandra Salomé, Sara Carinhas. Produção: As Boas Raparigas. Local e data de estreia: Estúdio Zero, Porto, 6 de Julho de 2011.

Mundividências, protagonistas, calamidades, números redondos, tendemos a reter da História o que é mais vibrátil e tem incontestada magnitude. Não será apenas uma questão de memória selectiva, é também um modo de nos protegermos, de separar por jurisdição as acções individuais, por que respondemos, dessa matéria mais abstracta que outros acharam merecer registo. A pedra, de Marius von Mayenburg, parece-me expor a conveniência desse hiato de percepção para um número significativo de alemães contemporâneos do Terceiro Reich. Refiro-me àqueles que, não partilhando o fervor da alucinação colectiva, foram de alguma forma coniventes, os que num contexto de maniqueismo, tal era a urgência de demarcação, souberam ser "dos deles". A gestão desta herança surge a par de um problema mais imediato, o da manutenção da propriedade num país de fronteiras e tutelas tão díspares em tão pouco tempo. Será possivel saber-se em definitivo a quem se refere um "a quem de direito"? É a partir de um longo retrato de familia que Mayenburg aponta as principais fragilidades da construção da identidade alemã no pós-guerra e no pós-reunificação. Ao escolherem produzir um texto como este, As Boas Raparigas abriram naturalmente espaço a uma reflexão que retoma estas questões e as amplia. Estamos ainda num continente minado pelo desfasamento entre nacionalidades e etnias, onde o descalabro financeiro parece justificar certo messianismo autoritário, lembrado com nostalgia; a recordação por branquear impôs-se-Ihes como necessidade, e ainda bem.

0 espectáculo acompanha uma familia de Dresden entre 1935 e 1993. Os momentos de charneira para esta família coincidem com períodos históricos de turbação, contudo Mayenburg narra impondo um filtro, o do apego à casa, e evitando o conforto da sequenciação cronológica. A História é assim amortecida por uma reconstituição subjectivamente ritmada, organizada em torno de um território que soma violentas conversões. A casa dos Schwarzmann, judeus forçados a emigrar, é depois a casa de Witha e Wolfgang, segundo ele "alemães decentes", que herdam as agressões dirigidas aos anteriores proprietários. A casa é parcialmente destruída nos bombardeamentos de 1945 e a família fica reduzida a mãe e filha, que alguns anos mais tarde hão-de partir rumo ao Ocidente. Sob o regime soviético, Witha e a filha Heidrun, já grávida, voltam a Dresden e travam conhecimento com Stefanie, uma das crianças das três familias que a casa alberga; em troca de uma visita ao jardim, Heidrun alicia Stefanie prometendo enviar-lhe chocolate anualmente. A queda do muro de Berlim e a posterior reunificação abrem caminho à restituição da propriedade. Witha e Heidrun, a quem se juntou Hannah, a terceira geração, regressam a uma casa que não Ihes é 


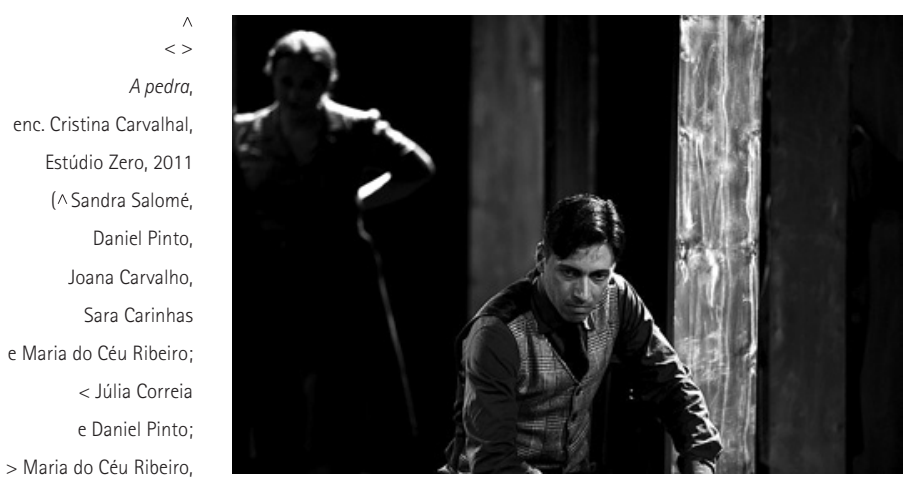

Sandra Salomé,

Júlia Correia

e Sara Carinhas),

fot. As Boas Raparigas.

de todo cómoda. Ao desenraizamento de Hannah e às assombrações de Witha junta-se agora a aparição de Stefanie, que reivindica o seu direito à casa e às tabletes que the são devidas.

Não querendo reproduzir um quadro doméstico reconhecivel, a opção foi a de instalar uma atmosfera. Sobrevém primeiro a impressão de austeridade e esquadria: a luz fria revela arestas, padrões - nos figurinos, a quadrícula, nos grandes volumes, o rectângulo - e o predomínio do preto e branco. Há um conjunto de peças verticais - sugestão de umbrais, janelas, sofá ou piano que reconheceremos a dada altura como a moderna, inabitável, mobilia dos Schwarzmann, mas conforme o texto avança certa incidência de luz concorre para outras sugestões, a de pedra tumular ou bancada inoxidável. Estas peças multiformes são ao mesmo tempo postos de vigia para quem está nas imediações da cena; não há bastidores nem repouso, o movimento dos actores é sempre atento, o de uma perpétua ronda. À medida que sucessivas versões dos factos nos aproximam do que terá efectivamente acontecido, percebemos o sentido do monocromático, do metálico, da tensa observação, para a construção do lugar em que se opera uma escrupulosa assepsia. É esse mecanismo que transforma Wolfgang, obediente funcionário do regime e suicida, em avó-herói vitima de uma bala perdida das tropas russas, benemérito financiador dos americanizados Schwarzmann, que afinal nunca chegaram ao destino.

Por muito que As Boas Raparigas nos tenham habituado a um patamar de exigência, naquela que é a segunda encenação de Cristina Carvalhal para a companhia é inevitável destacar o trabalho de direcção de actores. Este volante rigoroso determina a eficácia da narrativa, apesar de todas as síncopes, e potencia a produção de ambivalência. A responsabilidade de percorrer todo o arco cronológico cabe a Maria do Céu Ribeiro, que o faz com subtileza, com um esforço de composição quase miniatural.
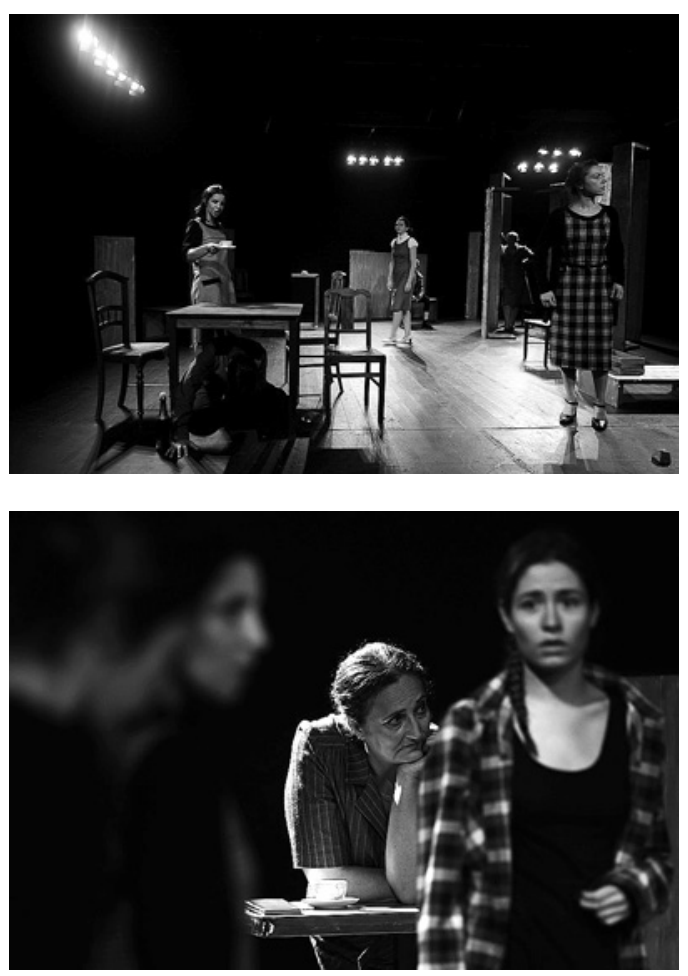

É assombroso, por exemplo, o trânsito da notação física e vocal da jovem esposa para a surdez, o alheamento e certos sintomas de stress pós-traumático na velhice. No entanto, esta caracterização seria inútil se não fosse acompanhada de elasticidade moral. E, de facto, globalmente os intérpretes situam as personagens numa zona parda, em que não há vítimas nem vilões absolutos há pessoas suficientemente maleáveis sob as suas circunstâncias. Interpretações particularmente vigorosas foram também as de Júlia Correia, uma Sra. Schwarzmann orgulhosa, insinuante, lúcida em relação à sua desvantagem e ainda assim atacante, e Sandra Salomé, a Heidrun que vemos crescer e, tal como a mãe, sacrificar a verdade para extrair mais profícuos exemplos.

A propósito de casas, talvez deva permitir-me uma última nota. Quando, em 2006, preparava para a Sinais de cena uma crítica a Curto circuito, pude ainda dar conta do improviso exemplar que esse espectáculo do Teatro Plástico originou: a ocupação do Rivoli. Desejaria agora ter algo de parecido a acrescentar. Sabe-se, desde meados de Março, que A pedra foi o último espectáculo de As Boas Raparigas no Estúdio Zero. E neste caso não há sequer a expectativa de que cheguem novos inquilinos: também se sabe que o recheio e equipamento foram retirados e que nada resta da feição do teatro de bolso que conhecemos. Triste facto consumado, este de contarmos mais uma companhia entre as que não conseguem manter tecto. Mas mais do que isso, perde-se uma sala intimamente ligada à crónica do teatro portuense desde a década de 80, tão necessária à produção própria como ao acolhimento. Talvez a funesta regularidade de factos consumados com que nos assaltam ajude a explicar o pudor da companhia: não houve um acto público, um mínimo sinal que envolvesse espectadores e cidadãos no esforço de manter a porta aberta. Talvez não fossem(os) tão poucos assim. 